\title{
COMPARATIVE STUDIES ON RAPID AND COST EFFECTIVE PROPAGATION METHODS AND INITIAL ESTABLISHMENT OF THE MEDICINAL PLANT Phyllanthus debilis KLIN EX WILLD (EUPHORBIACEAE)
}

\author{
K. N. S. Perera' \& K. U. Tennakoon² \\ 'Faculty of Applied Sciences, Sabaragamuwa University of Sri Lanka \\ 2Department of Botany, Faculty of Science, University of Peradeniya
}

Phyllanthus debilis Klein ex Willd. (Sinhala - Elapitawakka) is a widely used annual herb used in Ayurvedic medicine. The main objective of this study was to develop simple and cost effective propagation methods and growth media for initial establishment of $P$. debilis.

The experimental design was a completely randomized design. Fresh fruit samples at four different stages (light green, dark green, blackish green and brownish yellow) of maturity were used to determine the best maturity stage that gives the highest percentage. Seeds obtained from blackish green fruits gave the highest percentage germination $(92 \%)$ when grown on wet filter paper. Percentage of seed germination in dark green and brownish yellow fruits on wet filter paper were $26 \%$ and $65 \%$ respectively and $22 \%$ and $12 \%$ respectively when coir dust: sand $(1: 1)$ medium was used. Seeds obtained from light green fruits did not germinate. Upper and lower stem cuttings of $P$. debilis showed very low percentage success $2 \%$ and $7 \%$ respectively. Seed moisture content was determined using four seed samples $(n=100)$ dried at $103^{\circ} \mathrm{C}$ for 17 hours. The average moisture content of a seed was $15 \pm 1 \%$. Hence it can be regarded as an "intermediate" seed type. The seed. viability was tested at weekly intervals for nine weeks. The highest percentage of germination $(82 \%)$ was observed in onc-week-old seeds. Seed viability decreased gradually over the nine-week period and none of the seeds germinated after nine weeks of storage. Nine different potting media were tested for the initial establishment of $P$. debilis. Plants grown $(n=20)$ in the medium comprising top soil: compost: sand $(1: 1: 1)$ performed well in terms of plant height, leaf number and root collar diameter than in the other potting media.

Financial Assistance provided by Sri Lanka Conservation and Sustainable Use of Medicinal Plants Project is gratefully acknowledged.

Proceedings of the Eighth Annual Forestry and Environment Symposium 2002 of the Department of Forestry and Environmental Science, University of Sri Jayewardenepura, Sri Lanka 